\title{
Subjective well-being and self-regulation of educational activities of students in a digital educational environment
}

\author{
A.M. Timokhin ${ }^{1 *}$, L.V. Bura ${ }^{2}$, and V.V. Selivanov ${ }^{3}$ \\ ${ }^{1}$ V.I. Vernadsky Crimean Federal University, Simferopol, Russia \\ ${ }^{2}$ V.I. Vernadsky Crimean Federal University, Simferopol, Russia \\ ${ }^{3}$ V.I. Vernadsky Crimean Federal University, Simferopol, Russia
}

\begin{abstract}
As it is well known, digitalization of many aspects of modern society has become an urgent topic in the XXI century for most developed countries. The field of education is experiencing a rapid development of digitalization; distance learning is becoming one of the main forms. This impulsiveness has caused many problems, both organizational and psychological, since reality is not yet fully ready for revolutionizing teaching methods and ways of obtaining knowledge by the student audience. That is why the transformation of education into such an important social sphere requires the efforts of representatives of many scientific disciplines, including philosophers, sociologists, culturologists and psychologists. The latter, in addition to theoretical justifications, conducted also some empirical studies of the psychological adaptability of young people to new learning conditions. One of them is the proposed study, which is based on the assumption that student satisfaction with work in a distance format during the period of self-isolation depends largely on their subjective well-being.
\end{abstract}

\section{A problem statement}

As the study of activities in the process of distance learning shows, satisfaction with learning, in other words, subjective well-being is the most important, but unclear factor that increases educational motivation and effectiveness of a student. A decrease in satisfaction with distance learning affects negatively the effectiveness of the educational process, leading to negative consequences of the student's mental state: facts of apathy and depression, worsening of discipline, facts of deviant attitudes associated with aggression and despair.

On the other hand, a student who is satisfied completely with distance learning is an individual oriented towards independent development, and because of his age he may not be aware of what is useful for his learning and what is not. Such a student develops a strong desire for improvement (professional and personal), which in turn reduces the intensity of motivational energy, worsens interest in the development and effectiveness of his own

* Corresponding author: prof-ped.gpa@mail.ru 
educational activities, and also increases apathy and depression. That is why the students' satisfaction with distance learning should not be the greatest, but the best.

This research is aimed at an advanced study of the psychological mechanisms of selfregulation, motivation for learning activities and the subjective well-being of students studying in a digital educational environment.

M.A. Abramova and M. Farnika emphasize that the existing approach to the analysis of digital participation allows us to address the existing "digital gap", but does not provide an answer to the question of how to protect human capital in the periphery. In particular it shows that the realization of the concept of the "knowledge society" will become the reality only for these people ... The implementation of the principles of openness and accessibility in the field of education and information technology allows us to create a more flexible education system that will create socio-cultural prerequisites for remote and underdeveloped territories in solving a new task - creating universal digital literacy in the country and eliminating social problems caused by the growing digital inequality" [1].

Reznichenko N.S., Taptygina E.V., Morozova T.D. claim that "an integrated approach is needed to assess the transformation in the process of information changes in the field of modern education". The comparative analysis of existing models of "integrated vision" in the context of digital transformation of education and a critical review of its content allow us to determine that higher education using complex epistemological principles in educational research is an area of cognitive complexity, in which the development of creativity and adaptability is necessary for the successful implementation of activities in conditions of a highly unsteady social environment" [2].

Osin E.N., Leontiev D.A. note that "the introduction of distance learning technologies into the educational process is becoming a necessity for universities, since they not only create its image, but also serve as a pass to the world market" [3].

In his scientific works, S.N. Martyshek comes to the conclusion that "for today's youth, the global information and communication environment is an element of everyday life. In this environment, young people are placed in the framework of independent business decision-making, in terms of the level of trust in information and those who create it, as well as in terms of the possibility of inclusion into various informal groups of interest. The Internet does not only open up new opportunities for young people, but brings new threats. The Internet in the modern world is becoming an important factor influencing the value system of young people". The author also says about the need for the systematic development of special content for young people on the web: "Young people are not always able to navigate the flow of information and avoid negative consequences. Without active work of the state, it is impossible to resist the spread of bad content in the information space of the Internet" [4].

We believe that the use of digital technologies in education has become a global priority. In the studies of some scientists, it can be seen that digital technologies are resources for improving the quality of education and developing the abilities of modern youth. The traditional education systems do not adapt well to the changing nature of learning, requirements for students and their abilities, and to new ways of learning. In this regard, there is an increase in the deviant behavior of students and, thus, depression is inevitable [5].

In general, the review of scientific works allows us to conclude that in the process of self-isolation there is no established perception of the content and structure of distance learning, its specific features are not characterized, the interaction of social, pedagogical and psychological factors of student satisfaction with distance learning is not distinguished. This understanding of the problem being undecidable, both theoretically and experimentally, forms the basis of our research. 
The main link in determining the characteristics of self-regulation of educational activity is the goal of subjective acceptance. In order to organize a series of actions in accordance with the acknowledged goals, it is necessary to connect the goals with the real conditions for their achievement and to identify the most important conditions in terms of goals. On the basis of this model, a person realizes the regulating of actions, means and methods in the "course of action" link. At the same time both models and programs can change and adapt to each other in the process of activity. The goal remains the same (until one person achieves it or abandons it in favor of another goal).

As experience shows, there are differences between students in modeling the nature of conditions, in their choice of the preferred course of action, since the same goals can be achieved in different ways.

From a practical point of view, it is important to remember that a single functional regulatory structure in a particular type of activity is achieved by various psychological processes: perception, memory, thinking, etc. In this regard, the analysis of the functional structure of the educational activity of students is of particular interest. On the one hand, we can study changes in the connection between the self-regulating system and the psychological processes in which it occurs, on the other hand, the study of psychological processes, taking into account their connection with self-regulatory functions, will allow us to trace their formation and development in a new way in the learning process. Besides, the regulatory approach allows you to analyze the development of the student's qualities as a regulatory subject in the learning process, which makes it possible to move from learning to self-learning, self-education and self-improvement. However, in order for these processes to become a reality, it is important to have an idea of the self-regulating reference property that a student will have not only in current needs, but also in future professional activities [6-10].

Based on the analysis of this problem, it was established that in pedagogical work with students, it is also necessary to develop the ability to plan the implementation of educational activities specially. The ability of a person to determine the deviation of the implemented activity plan from the given activity plan and to adjust it is closely related to planning and self-control. With self-control, many psychological processes develop: attention, will, self-awareness.

The development of self-awareness is inextricably linked with a person's thoughts on himself and his abilities. It is known from the work of psychologists how the lack of understanding of one's abilities affects person's actions and their productivity. In university practice, one often has to deal with a discrepancy between students' self-esteem and real abilities.

The abilities and ideas of students about themselves are formed under the influence of various factors. Often, students who have an overestimated or underestimated idea of their abilities transfer them to future professional activities. This is mainly due to the fact that they have insufficiently developed ability to analyze their achievements and failures, the specific results of their actions. Even for graduate students, the results and analysis of the conditions for achieving them turn out to be inadequate [10-13].

In the course of our research, it was found that as students were moving up the educational ladder, with the accumulation of experience in secondary school and experience of relationships with young people of the same age, self-esteem of students changed significantly. Besides, the nature of dependence on "relationships" and "activities" has changed. As a rule, the majority of talented students rate their achievements in activity lower than the teacher. However, "weak" students rate their achievements much higher than the teacher. 
Education and training, as well as work practice help students to assess their own capabilities more accurately. After them students are characterized not by a conscious attitude to their capabilities and successes, but by increased reflection.

\subsection{The objective of the work}

Based on the theoretical analysis of students' satisfaction with distance learning the methods of M.B. Sokolova was applied, which is aimed at analyzing the emotional component of subjective well-being.

The first-year students of various specialties of the Federal State Autonomous Educational Institution of Higher Education "V.I. Vernadsky Crimean Federal University" were tested in the course of the research, where a total of 100 students, aged from 18 to 20, took part.

\section{Results of the research}

First the students were offered the "Scale of Subjective Well-Being" methodology, with the help of which a study was carried out in the field of the psychology of stress and its effect on human health. The scale is a tool for measuring the component of subjective well-being or emotional comfort. The methodology consists of 17 questions, the content of which is related to the emotional state, social behavior and some physical symptoms. According to the content, the items are divided into six clusters: tension and sensitivity; signs accompanying the main psychiatric symptoms; change in mood; the importance of the social environment; self-assessment of health; satisfaction with daily activities. The distribution of diagnostic results by levels of subjective well-being in the group of students is shown in Figure 1.

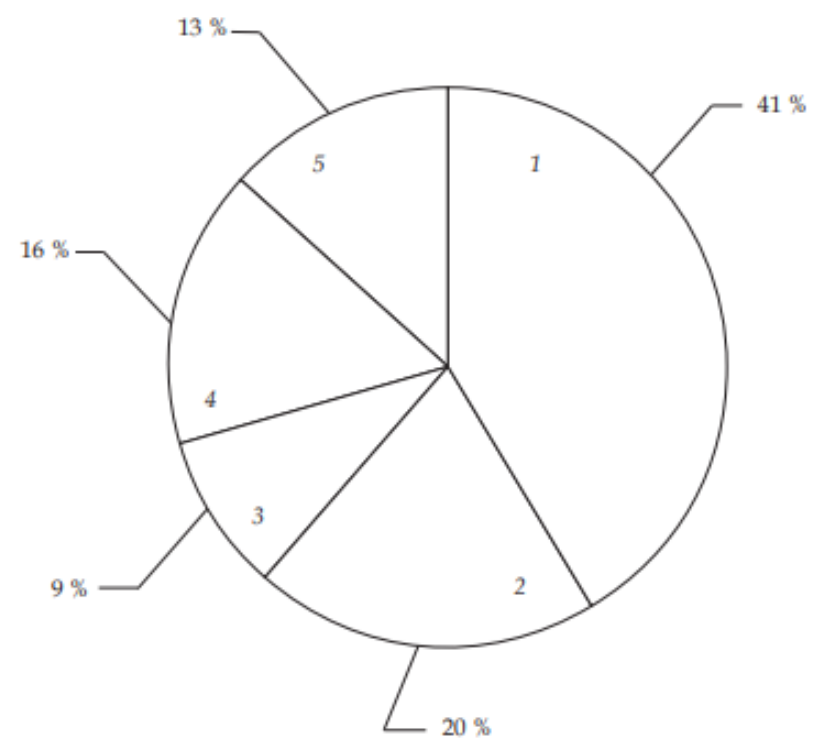

Fig. 1. The distribution of diagnostic results by levels of subjective well-being in a group of students. I - ML (4-7 sthenes); 2 - HL (8-9 sthenes); 3 - ExHL (10 sthenes); 4 - LL (2-3 sthenes); 5 - ExLL (1 sthene).

Note: ML - medium level; HL - high level; ExHL - extremely high level; LL- low level; ExLL extremely low level 
The results of the study of the characteristics of the subjective well-being of the group of freshmen, which included an assessment of the quality of emotional experiences of those who were tested in the range from optimism, happiness and self-confidence to depression, irritability and loneliness, made it possible to distinguish the following characteristics:

- the majority of students (41\%) showed an average degree of the studied quality: respondents with similar assessments were characterized by moderate subjective wellbeing, in which there were no anxious difficulties, but also there was no complete emotional well-being;

- $20 \%$ of students showed a high level of subjective distress: perhaps the reason is a personal predisposition to depression, anxiety, poor adaptability to changes of situations;

$-12 \%$ of the students tested experienced moderate emotional comfort and, we can say that they adapted well to the new training system: they did not experience obvious emotional problems, remained self-confident, dynamic;

- $9 \%$ of students showed obvious emotional discomfort, the reasons for which may be associated with their personal qualities: the presence of an inferiority complex, fear of novelty, lack of flexibility, doubts about imaginary difficulties, lack of unity in the environment;

- $13 \%$ of students had complete emotional well-being and did not have serious psychological problems. These respondents have good adaptability, a high degree of resilience and self-organization. They also have a sense of purposefulness that helps them to get used quickly to the new curriculum.

Assessing the diagnosis of the subjective well-being of the group of students, the following characteristics can be distinguished: the majority of students have a general satisfaction with their daily activities in a new learning environment, subjective well-being is normal, and there is no psychological state. It should be noted that some students experience emotional discomfort. Of particular concern are students whose indicators show lack of emotional well-being, low stress tolerance, and health problems ( $9 \%$ versus $20 \%$ ).

Analyzing the results of studies of satisfaction with individual and group work in a distance format, we should note that the majority of students $(25 \%)$ are satisfied with their work, $13 \%$ are quite satisfied with their work, but $18 \%$ of students in the group are very dissatisfied.

The general conclusion of the study of all the parameters of the distance format and subjective well-being of job satisfaction showed that in this group the level of subjective well-being was medium and low for the majority of students, and the data obtained for the remote format of job satisfaction showed a relationship between the level of subjective well-being and satisfaction with work at a remote format. To prove this hypothesis, a correlation analysis was carried out using Spearman's rank correlation coefficients.

Based on the results of the study, it can be concluded that the following psychosocial factors that characterize his subjective well-being affect the student's satisfaction with distance work: interest in distance learning; satisfaction with the conditions of remote work, relations with classmates, satisfaction from interaction with teachers, satisfaction with working conditions; the level of professional responsibility of teachers.

\section{Conclusions}

In the conditions of university education, students gradually discover new opportunities for themselves to become a subject of activity. As the awareness of their activity and the conscious analysis of their management moments, combined with constant practical tests of their ability for academic work grow, students try to make the regulation of their participation in activities more effective. Significant changes in this sphere were distinguished at the final stages of university training, when self-regulation of activities and 
self-regulation of the individual reached their peak, namely, when students were interested not only in the results of their educational efforts, but also in their professional status, their abilities.

Within the activities of the distance format, in the minds of students, to some extent, a system of ideas about their abilities has been formed:

1) goal setting (you need not only to be able to understand the proposed goals, but also to implement them);

2) modeling (you need to be able to determine the conditions that are important for the implementation of the goal, find the idea of the desired topic in your experience and find an object corresponding to this topic in surrounding situations);

3) planning (you must be able to determine the order of performing of every action);

4) evaluation (you need to be able to evaluate the final and intermediate results of your actions);

5) correction (you need to imagine what changes can be included to the results if some details do not meet the requirements);

6) relationships (you must have an idea of the manners of relationships with other people and the object of labor).

When we talk about a student as a subject of educational activity, about a conscious self-regulating system of his activity, we mean that, on the one hand, he must have a clear system of ideas about his ability to solve various kinds of self-regulating tasks, on the other hand, a system of skills formation associated with these views. Only in this way students will be able to set their own goals, coordinate them with the requirements of the environment and keep them in the sphere of consciousness in the field of self-regulation until they are achieved.

Students can acquire these skills and abilities not through psychological understanding, but only directly in the process of their implementation.

Thus, based on the results of the study, it can be concluded that the following psychosocial factors that characterize his subjective well-being affect the student's satisfaction with distance work: interest in learning regardless of the teaching method; learning effects associated with the positive aspects of remote work; the ability to maintain relationships with classmates; high-quality interaction with teachers.

All of the above mentioned allows us to make a conclusion about the importance of improving the quality of interaction between subjects of educational relations, especially when teaching in online formats. Satisfaction with life, which satisfies the basic psychological needs of students in interaction, both between them and with teachers, plays an important role in the development of learning motivation and self-regulation of learning activities. The data obtained make it possible to reconsider the possibilities of online learning, mainly from the point of view of the quality of interaction between participants in educational interactions. The format of the organization of distance (online) learning, the quality of interaction between students and teachers, which have arisen and are being implemented in distance educational institutions, often contribute to the development of educational motivation and self-regulation of students' online learning, which is reflected in the study.

\section{References}

1. M.A. Abramova, M. Farnika, Digitalization of Education in the Context of Digital Inequality, Professional Education in the Modern World, 9 (4), 3167-3175 (2019) 
2. N.S. Reznichenko, E.V. Taptygina, T.D. Morozova, Comparative Analysis of the Quality of Distance Learning for Students, Siberian Medical Review, 4 (70), 99-103 (2018)

3. E.N. Osin, D.A. Leontiev, Brief Russian-Language Diagnostic Scales for Subjective Well-Being: Psychometric Characteristics and Comparative Analysis, Monitoring of Public Opinion: Economic and social changes, 1, 117-142 (2020)

4. S.N. Martyshek, The Influence of the Internet on the Formation of the Communicative Environment of Modern Youth, Azimuth of Scientific Research: pedagogy and psychology, 1 (30), 185-189 (2020)

5. I.E. Sokolovskaya, Digitalization of a Teacher as an Important Process of Development of Learners, Human Capital, 12-2, 540-544 (2019)

6. D.A. Leontiev, Personal Potential: Structure and Diagnostics, 680 (Moscow: Sence, 2018)

7. L.A. Alexandrova, A.A. Lebedeva, V.V. Bobozhei, Psychological Resources of Personality and Socio-Psychological Adaptation of Students with Disabilities in the Context of Vocational Education, Psychological Science and Education, 19 (1), 50-62 (2017)

8. A.A. Verbitsky, Context (in Psychology), 137-138 (M., 2016)

9. T.O. Gordeeva, Self-Determination Theory: Present and Future, Psychological Research: electron. scientific. journ., 4 (12), 5-12 (2017)

10. A.A. Grebenyuk, The Influence of the Internal Characteristics of New Media on the Mentality and Mental Health of a Modern Person, Azimuth of Scientific Research: Pedagogy and Psychology, 1 (30), 337-339 (2020)

11. M.A. Odintsova, M.G. Kulyatskaya, Psychological Well-Being of Students with Disabilities in an Inclusive Mixed Learning Environment, Psychological and Educational Research, 11 (2), 30-42 (2019)

12. K.A. Tatarinov, Methodological Aspects of the Development of Multimedia ELearning Courses, Azimuth of Scientific Research: Pedagogy and Psychology, 1 (30), 227-280 (2020)

13. V.V. Tonkonog, P.I. Ananchenkova, Distance Learning in the Regional Educational Space in the Process of Training Students of Different Directions and Specialties, A Businessman's Guide, 35, 284-293 (2017) 